\title{
LA MEMORIA Y SU SILENCIO: DESCRIPCIÓN DE LA MENTIRA (1977), DE ANTONIO GAMONEDA, Y LA MEMORIA CALLADA DEL FRANQUISMO Y DE LA TRANSICIÓN
}

Juan José LANZ

UPV/EHU

\section{RESUMEN}

Partiendo de las tesis de Marc Augé, se trata en este artículo de investigar cómo memoria y olvido, y sus correlatos escriturales (relato y silencio), y epistemológicos (mentira y verdad) tejen una tupida tela en Descripción de la mentira, de Antonio Gamoneda, para traer al presente la memoria reprimida de los derrotados tras la guerra civil y hacer que ese relato interfiera en la construcción del momento transicional. Descripción de la mentira reconstruye así la memoria del olvido durante el franquismo y la transición política y ofrece un nuevo modelo de actuación de la escritura poética en la Historia.

Palabras clave: Gamoneda, Descripción de la mentira, memoria, Franquismo, Transición.

\begin{abstract}
In Descripción de la mentira, Antonio Gamoneda uses memory and oblivion, silence and story, lie and truth, to bring to the present moment the supressed memory of those who were defeated in the Civil War, and to make this silenced story to meddle in the construction of the spanish Transition.
\end{abstract}

Key words: Gamoneda, Descripción de la mentira, memory, Transition, Franco’s regime.

Es justo admitir que retratar a los socialmente invisibles (por ejemplo, las mujeres trabajadoras) o escuchar a quienes no se expresan (la mayoría silenciosa, los muertos) es un cometido que implica mayores riesgos que los habituales en la historia tradicional (si bien resulta necesaria como parte de la historia total).

Peter Burke, Formas de hacer Historia. 
La muerte de Franco abre un período dentro de la política y de la cultura españolas que se define precisamente por su indefinición, por una conciencia de transitoriedad que caracteriza su presencia histórica y que hace de él un ámbito de posibilidades que sólo unos años más tarde se restringirán. Si algo define justamente la Transición es esa conciencia de hallarse en una indeterminación absoluta que caracteriza los tiempos de crisis; se mide precisamente en ese vacío, en esa detención que se produce en un momento en que lo obsoleto aún no ha desaparecido y no ha nacido aún un nuevo sistema de recambio. La Transición se define como una frustrada posibilidad absoluta, como un momento histórico de infelicidad radical y desengaño anunciado que se caracteriza por la posibilidad de la materialización de todas las utopías, pero también por la conciencia de su fracaso, por su escepticismo radical. Porque si algo había logrado el régimen en sus casi cuarenta años de férrea represión, era no sólo anular las posibilidades reales de libertad, sino también el sueño de esa posibilidad, la castración de cualquier sueño utópico; había logrado inseminar en buena parte de las conciencias críticas el espíritu del fracaso, de la frustración que se vinculaba al final de su existencia. Es el resultado de cuarenta años de una dictadura fundada en un régimen enmascarado en un paternalismo castrador y arbitrario que gobernaba los designios de sus súbditos por decreto. En su lógica psicológica, la figura del padre castrador extiende su influencia más allá de su presencia física y frustra toda pulsión, toda construcción, más allá del estricto reducto en que ejerce su poder.

Muerto Franco, había que comenzar a construir un nuevo sistema, una sociedad nueva, y un modo de pensar diferente, pero los cuarenta años de dictadura habían conseguido arrancar toda posibilidad de hacerlo. Lo que había que hacer por encima de todas las cosas era construir un lenguaje distinto: una semántica no corrompida que recompusiera los significados exactos de los términos usurpados por la dictadura; una sintaxis que estableciera nuevas conexiones entre los términos, entre los conceptos, que reflejara una transformación radical, que manifestara nuevas asociaciones para disociar las relaciones instituidas. En fin, hacía falta la constitución de un nuevo lenguaje y de un nuevo relato de los hechos históricos usurpados por el oprobio y el silencio, para así construir un relato fidedigno del presente. A ello se dedican muchos de los textos que se publican en ese período transicional; y no pienso en aquellos que, con la voluntad consciente o inconsciente de adecuarse a las nuevas circunstancias, llevan a cabo un Descargo de conciencia que implica una narración autoexculpatoria de los acontecimientos y relatos en los que habían participado activamente, sino en aquellos otros que desde las trincheras de la resistencia activa intentan establecer un nuevo sistema aún sin definir, y una nueva lógica de la narración de los hechos y, en consecuencia, 
una nueva lógica del relato, pues al fin y al cabo los hechos no son otra cosa que su relato: el Juan Goytisolo de Juan sin Tierra (1975), el José Manuel Caballero Bonald de Descrédito del héroe (1977) o el Antonio Gamoneda de Descripción de la mentira (1977). Son sólo tres ejemplos, pero su relación en la distancia me parece evidente.

El olvido es justamente la plasmación perversa del silencio que el régimen había impuesto a cuarenta años de agravios, del silencio en que lee Antonio Gamoneda en Descripción de la mentira, que puede entenderse precisamente como una profunda lectura del silencio, como una construcción del olvido, como una poética de la desocupación del espacio, como una construcción de la oquedad. El olvido, como modo de supuesta reconciliación nacional, supone el último triunfo de un régimen dictatorial que se sobrevive a sí mismo, la eliminación de la memoria histórica, el triunfo del relato de los acontecimientos tal como machaconamente se había venido repitiendo durante años. Descripción de la mentira levanta todo un monumento frente al silencio, que se construye precisamente como silencio; un monumento frente al olvido, que se construye justamente haciendo patentes las ausencias. Es otra forma de olvido, que no se caracteriza por la eliminación de la memoria, sino, más bien al contrario, por la recuperación de los huecos que deja el recuerdo. Tal como señaló Marc Augé en Las formas del olvido: «Llevar a cabo el elogio del olvido no implica vilipendiar la memoria, y mucho menos aún ignorar el recuerdo, sino reconocer el trabajo del olvido en la primera y detectar su presencia en el segundo. La memoria y el olvido guardan en cierto modo la misma relación que la vida y la muerte» (Augé, 1998: 19). Recientemente, el poeta ha escrito al comienzo de sus memorias, Un armario lleno de sombra, que «en el olvido están los recuerdos». Su poesía, como sus recientes memorias, pueden entenderse perfectamente desde esta perspectiva: «penetrar en el olvido y hacer intelectual y sentimentalmente presente lo que parecía no estar ya en mí ni en nadie» (VV. AA., 2008: 31). En este sentido, penetrar en el olvido implica actualizar la memoria de la ausencia, hacer presente lo que estaba ausente, traer ante los ojos lo que estaba reprimido, lo tantas veces omitido en el silencio, lo que se ha sembrado en la sombra de la desmemoria. El retorno de lo reprimido implica también la construcción de una memoria, en este caso una memoria de los hechos acaecidos bajo la dictadura franquista, que se hace presente en su ausencia, pues nace con la conciencia de su incapacidad para habitar el espacio de la Historia que le corresponde (Gamoneda, 2006: 29 y ss.). El retorno de lo reprimido, la recuperación de los huecos del olvido que se tejen en el espacio de la memoria, que sustentan los pilares del recuerdo, no implican la suplantación de los acontecimientos que tejieron la Historia, por otros, sino el intento de subvertir el relato del pasado que se hace, y que es, en todo caso, un 
relato de poder. No hay posibilidad de volver a habitar los huecos del olvido, de reintegrar la ausencia y lo usurpado al tiempo histórico en que se vivió, pero sí de transformar, mediante su evocación reflexiva y crítica, el relato del presente. $\mathrm{Si}$, como veremos, Descripción de la mentira, reconstruye el relato de los hechos silenciados bajo la dictadura franquista, si relata el silencio de los humillados y vencidos tras la guerra civil, no es sólo por una voluntad de justicia histórica, por un intento de reintegrar en el relato de la Historia que se hace desde el presente la memoria negada, sino fundamentalmente por una voluntad de actuación sobre el presente transicional en que el libro toma forma en cuanto relato, en tanto en cuanto la memoria del oprobio silenciado determina, frente a otros relatos triunfantes, el relato del presente que comienza a realizarse tras la desaparición física del dictador. De este modo, Descripción de la mentira y en general la obra toda de Gamoneda puede decirse que se constituye en un documento histórico de especial valor, porque, tal como ha señalado Fernando R. de la Flor, instrumenta «una innominada figuración espectral de lo histórico» (VV. AA., 2008: 8); y lo hace en tanto en cuanto que evoca una memoria usurpada por el franquismo y la hace actuar en el presente de la escritura (la escritura siempre es en presente) de dos modos diferentes y complementarios: con una voluntad de interferencia sobre los relatos del pasado inmediato que se actualizan en su vigencia en el período transicional; con una voluntad de integrar un modo diferente de construcción del presente transicional, que condicione la realización de un modelo distinto de futuro. No hay nostalgia, no hay elegía en la escritura poética gamonediana y no debería resultar extraño en una escritura que se teje en la desmemoria del olvido.

El recuerdo es la construcción del relato en el que adquiere sentido nuestra existencia, mientras que el olvido es la materialización de las huellas de la ausencia que conforman dicho relato; esas huellas de la ausencia sólo pueden materializarse en el silencio, en la carencia, en una poética de la oquedad, en la construcción de un hueco que hace visible lo invisible, el vacío, lo negado: «Harías mejor abandonando, deshabitando un tiempo que se coagula en la dominación»; «Cuanto ha sucedido no es más que destrucción». El olvido forma parte integrante de la memoria, lo mismo que el silencio es parte constitutiva del lenguaje. Tengamos presente justamente el comienzo de Descripción de la mentira (Gamoneda, 2004: 171-222. Todas las citas, por esta edición):

El óxido se posó en mi lengua como el sabor de una desaparición.

El olvido entró en mi lengua y no tuve otra conducta que el olvido, y no acepté otro valor que la imposibilidad.

O las palabras con las que se inicia la última sección del libro: «El olvido es mi patria vigilada y aún tuve un país más grande y desconocido». «Me poseyó 
el olvido», «mi fortaleza está en recordar», escribe en otro lugar el poeta. La memoria se teje con los recuerdos y los olvidos necesarios, que dejan las huellas de su desaparición, y que sólo pueden hallarse en una estética de la negación. La lengua constata, por su parte, la ausencia de cuanto nombra; su silencio hace presente una ausencia. La lengua posee «el sabor de una desaparición» porque habla de lo oculto, de lo olvidado, de todo cuanto fue omitido, reprimido, y ahora regresa en su ausencia, como el envés de un relato callado:

La prosperidad de mi lengua se revela en cuanto fue olvidado durante mucho tiempo y sin embargo visitado por las aguas.

[...]

Habla de mí como una vibración de pájaros que hubiesen desaparecido y retornasen.

Es el retorno de la ausencia, la constatación de lo desaparecido, lo que plasman las palabras de Descripción de la mentira. No hay tanto la rehabilitación de un relato usurpado, sino la constatación de la falsedad del relato usurpador. Y, en ese sentido, Descripción de la mentira constituye un modelo de excepción de una memoria atípica y atópica del franquismo. El cuestionamiento de la mentira histórica, pero también existencial, como veremos más adelante, no recupera un discurso abolido, que no tendría validez histórica fuera del tiempo en que se incardinaba su existencia («Pero aquel tiempo no existió: sucedió en la inmovilidad como la música antes de su división»), sino que permite su lectura palimpsestuosa como borrado (Gamoneda, 2006: 15-16); permite su actualización como ausencia, como retorno de la desaparición que se constata en dicha desaparición y que transforma el propio relato histórico del presente en que se inserta. Porque, desde una lectura como documento histórico, Descripción de la mentira no es sólo el relato de la memoria elidida de la represión bajo la dictadura (la «tortura», la «traición», la «delación», las «paredes ensangrentadas», etc.), sino también el relato del presente histórico, en cuanto éste es consecuencia de aquélla, en que se inserta y al que condiciona. En cierto modo, lo que apunta Descripción de la mentira es justamente la continuidad histórica de dos tiempos que se pretenden distintos. Y entonces sí cobra relevancia histórica y documental la narración sincopada, en cuanto que la rememoración de un pasado negado, olvidado, se actualiza en el relato del presente. No, Descripción de la mentira no es sólo un relato del pasado, no es sólo la evocación de las ausencias, de lo negado obstinadamente por el discurso de la Historia que se construye en la posguerra desde el poder omnímodo de la dictadura, que reaparece en su dimensión espectral en el presente, puesto que todo acto de escritura es presente, sino que es un relato del y en presente. No hace falta más que recordar la última línea del poemario: «¿Qué hora es ésta, qué yerba crece en nuestra juventud?» Sus 
preguntas, y no olvidemos que el libro es fundamentalmente una inquisición epistemológica que se cuestiona constantemente por la verdad ( ¿iQué verdad existe en el vientre de las palomas?») para desvelar la descripción de la falsedad, de la mentira, arrancan del pasado elidido pero se dirigen al presente («iQué lugar es éste, qué lugar es éste? ¿Cómo estás aún en mi corazón?», «¿Qué hora es ésta?»), que no es sólo consecuencia de la actualización visionaria del pasado, sino de la permanencia de éste en cuanto ausencia en el relato. Al fin y al cabo lo que la narración sincopada de Descripción de la mentira nos testimonia es el relato de lo que «queda de nosotros»: «Mi boca es fría en las plegarias. Este relato incomprensible es lo que queda de nosotros. La traición prospera en corazones inviolables». Es ahí donde cobra radicalidad histórica el relato que se incardina y subvierte la diégesis del presente histórico, que se narra a sí mismo la memoria del pasado inmediato para instaurarse en una nueva mentira, de la que el libro gamonediano descree, y siembra la descreencia, a cada paso. Frente a otros relatos exultantes que comienzan a aparecer durante la Transición, que marcan la disrupción histórica del nuevo momento con respecto al inmediato pasado, el libro de Gamoneda marca su continuidad; frente a otros modelos que marcan en ese momento la necesidad del olvido para una supuesta «reconciliación nacional», Descripción de la mentira insiste en la presencia de lo olvidado, en dar voz a la muchedumbre silenciosa que, durante la dictadura, ha hecho de ese silencio su salvaguarda.

Quizás esa capacidad visionaria del lenguaje que caracteriza Descripción de la mentira, como núcleo germinal de un mundo poético que se va a desarrollar a lo largo de treinta años, sea la única forma de presencializar el olvido, de hacer presentes sus huellas, las ausencias y las elisiones, los recuerdos omitidos por el relato del poder. Para una conciencia lúcida («me obligas a la lucidez sin causa»), para una conciencia poética desde la que escribe y en la que existe Antonio Gamoneda, la visión es siempre presente, es siempre actual; la visión nos otorga ese espacio en que lo olvidado aparece de modo inmediato y directo desprovisto de la mediación del recuerdo, se hace «intelectual y sentimentalmente presente». Lo perdido se recupera en su vacío, la huella aparece precisamente para denunciar la ausencia, el hueco, la carencia, y lo hace en el tiempo histórico de la escritura, que es siempre presente. No hay, por lo tanto, elegía en Descripción de la mentira porque no hay un canto del recuerdo en el pasado, sino un desvelamiento del olvido que acontece en el presente, que se hace presente a través de la visión.

Varias veces a lo largo de Descripción de la mentira insiste Gamoneda en la incomprensibilidad de su relato poético: «Nuestros labios envejecieron en palabras incomprensibles»; «Hay un relato y es la humedad que sucedió el mismo 
día de tu muerte»; «Este relato incomprensible es lo que queda de nosotros». A lo largo de Descripción de la mentira y a lo largo de la obra poética gamonediana, en general, se establece una tensión irresoluble entre relato y comprensión, entre ficción y dicción. Vuelvo a retomar las palabras con que cierra el adelanto de sus memorias que ha dado recientemente: «Escribir este libro, ajeno a ficción aunque en algún momento haya podido ser tomado por el pensamiento poético». Los recuerdos sólo se integran en la memoria como relato; se desprenden de su halo de pureza para integrarse en la diégesis. Por otro lado, nuestra vida es el relato de nuestra existencia que nos hacemos a nosotros mismos; es uno de los relatos posibles que podrían acontecer. Nuestra existencia, ya lo señaló Ortega, es fundamentalmente bio-grafía, en su sentido etimológico, vida escrita, vida narrada, vida contada. Nuestra existencia acontece en un cruce de relatos (sociales, históricos, personales, etc.) (Augé, 1998: 46-48) que apuntan a una dimensión netamente intertextual. Es precisamente a través del relato de nuestra existencia como ésta se dota de sentido, construye su sentido; del mismo modo que no es en los hechos, sino a través de su relato, como aquellos devienen comprensibles. Es el relato el que construye el recuerdo; es el relato, la bio-grafía, lo que hace comprensible nuestra existencia. Los recuerdos trazan en la memoria el relato en que el pasado deviene comprensible en el presente; sólo a través de ese relato construimos la memoria del pasado, que no es sino narración, y, por lo tanto, distancia, ficción. Ese relato acontece en cuanto que unos recuerdos se asocian con otros, y prescinden de otros, que son las huellas que quedan en el olvido. Se produce, por lo tanto, una sintaxis narrativa por la que, las omisiones, y, en consecuencia, la sincopación, permiten establecer una serie de conexiones y asociaciones en la que nos narramos (en presente) nuestra memoria del pasado. Muchas veces ese relato no es nuestro, sino que, en esa dimensión intertextual que he señalado, son otros (otros relatos) los que nos hacen asumir un relato como propio. En consecuencia, como se ha apuntado, la propia vida se construye como ficción, como distancia, desplazando los olvidos de la memoria, para asumir el relato de los recuerdos, que sólo subsisten en cuanto tal relato. Lógicamente un discurso que se fundamenta en el olvido, que hace legible el silencio que los recuerdos obvian, ha de constituirse como un «relato incomprensible», en el que las asociaciones y conexiones requieren una nueva sintaxis narrativa. Si el modo de ser del recuerdo es el relato, la diégesis, la narración, la ficción, la distancia, el modo de ser del olvido es el mito, la dicción, la poiesis, la presencia, que se materializa en la fragmentación y el silencio. Si el modo de ser del recuerdo es el relato, el olvido sólo puede hacerse presente como ausencia en la fragmentariedad, en la sincopación, que subvierte la sintaxis narrativa y que busca nuevas «asociaciones libres», es decir, que 
disocia las asociaciones instituidas y las sustituye por otras que cuestionan y disuelven el orden del discurso establecido, que es el orden en que el poder impone su relato del pasado. Pero no se trata de suplir un relato por otro, ya se ha dicho, sino de cuestionar la misma esencia del relato mediante un discurso que no afirma, sino que niega constantemente («Hay negación»; «Este es el único día digno de ser vivido ya que todos los otros días fueron días de negación»; «la negación ha tocado mi cuerpo»); un discurso que no instituye, sino que cuestiona.

«Las preguntas no existen en el idioma de la ocultación: todo está dirimido». Todo discurso es discurso de poder con voluntad de imposición. Todo relato, por lo tanto, pugna por imponer su verdad, su ficción, pero sólo descubre la falsedad que oculta en su voluntad impositiva, la Descripción de la mentira: «Líbrate de la libertad antes de entrar en mí». En consecuencia, un discurso desvelador que se pretenda sin voluntad de poder ha de establecerse como un discurso abierto, sin voluntad de imposición, debe evitar «la liturgia de la traición», que es el resultado de los discursos que establecen la verdad como su corolario:

De la verdad no ha quedado más que una fetidez de notarios una liendre lasciva, lágrimas, orinales y la liturgia de la traición.

No sólo debe negar constantemente, sino que debe cuestionar a cada paso su enunciación. Ese hecho justifica precisamente la retórica interrogativa que formula Descripción de la mentira y la estructura paradójica de muchas de las preguntas a través de las cuales construye su discurso como ruina («Siéntate en medio de las ruinas, siéntate con dulzura en el medio o al borde de las ruinas»), enuncia su relato desde su cuestionamiento, su presencia desde la huella de su ausencia: «¿Sabes qué es el olvido?», «¿La verdad está en la lengua o en el espacio de los espejos?», «¿Cuál es mi verdad?», «¿Qué sabes tú de la mentira, qué sabes tú de las sustancias soportables?», «¿Sabes tú lo que es la destrucción?», «¿Quién ha gemido tras el cinturón de álamos?», «¿Quién habla en ti, quién es la forma de tu rostro?», «¿Qué hora es ésta, qué yerba crece en nuestra juventud?» Todas estas preguntas estructuran el discurso poético de Descripción de la mentira para hacer del libro una gran pregunta, una búsqueda que no lleva a ninguna respuesta (o que hace de la pregunta, del cuestionamiento de lo evidente, su respuesta), sino a una serie de enunciados abiertos, paradójicos y contradictorios muchas veces, que denuncian toda voluntad de imposición de los discursos de poder sin establecerse a sí mismo como discurso de poder. Descripción de la mentira es, ya se ha dicho, una inquisición epistemológica que se cuestiona por la verdad de su tiempo para desvelar la descripción de la falsedad; es una búsqueda epistemológica que acaba afirmando el propio conocimiento como distancia, que acaba 
siempre apuntando un más allá de las palabras que enuncia; una búsqueda de conocimiento que acaba constatando el propio conocimiento como búsqueda. La verdad se materializa como ausencia («No recurriré a la verdad porque la verdad ha dicho no y ha puesto ácidos en mi cuerpo»; «la verdad conducía a la traición»), y el conocimiento se materializa como distancia.

Si la ficción es el lenguaje del recuerdo en cuanto relato, ¿cuál es el lenguaje del olvido?, ¿cómo podemos recuperar lo que no estaba en la memoria haciéndolo presente sin que ello suponga una falsificación, sin que ello quiebre su ausencia?, ¿cómo decir lo que permanece callado sin violar su silencio?, ¿cómo hacer una lectura del silencio?, ¿cómo lograr que el silencio hable sin que se quiebre su esencia callada? "Después del conocimiento y el olvido ¿qué pasión me concierne?", se pregunta la voz poética al comienzo del libro. La propia escritura de Descripción de la mentira se plantea, así, en su esencia paradójica:

¿Qué harías si tu memoria estuviera llena de olvido? Todas las cosas son transparentes: cesan las escrituras y cae lluvia dentro de los ojos.

Sólo el silencio, el cese de toda escritura puede plasmar el lenguaje del olvido; sólo el silencio puede constatar la presencia del hueco, del vaciado, de la destrucción, de la verdad elidida y usurpada sin construir una nueva falsedad, sin rellenar esa ausencia con una nueva mentira. "Cesan las escrituras» y las palabras se tornan «palabras incomprensibles». El silencio se convierte entonces en la palabra del olvido, que dice la ausencia sin falsearla, que hace presente lo elidido en su propia ausencia. Hay al comienzo de Descripción de la mentira una especie de euforia, de júbilo, por el abandono del silencio, por el acceso a una nueva expresividad que va a dar paso a un retorno a la escritura:

[... escuché hasta que la verdad dejó de existir en el espacio y en mi espíritu, y no pude resistir la perfección del silencio.

No creo en las invocaciones pero las invocaciones creen en mí:

han venido otra vez como líquenes inevitables.

$[\ldots]$

Durante quinientas semanas he estado ausente de mis designios, depositado en nódulos y silencioso hasta la maldición.

Pero pronto se percibe que esa locuacidad resulta peligrosa, que el lenguaje miente, falsea, inventa, es distancia, no recupera la memoria sino que siembra el olvido, como afirmaba Platón en el Fedro, y evidenció Derrida (1975); y sin embargo ésa es la fatalidad del poeta: «Es perverso el idioma pero es enjundia de mi cuerpo», afirma en un momento. Efectivamente, el lenguaje, la palabra, es el espacio de la mentira («Mientes en la deposición», «la mentira trabajada hasta que hierve en la boca»); el lenguaje es culpable de la represión impuesta por el régimen dictatorial, de la tortura («Mientras tanto la tortura ha pactado con las palabras»), de un sistema que hace de la retórica su construcción ideológica 
y represiva. Es en el lenguaje donde se manifiesta la usurpación de la verdad, donde se construye la mentira del relato de la historia reciente, pero también de la historia presente, la falsedad de una existencia inauténtica fundada en un tiempo histórico vivido como mentira; es en el lenguaje donde se teje la mentira de la memoria impuesta; es en el lenguaje donde la «traición» nombra, donde se da la «delación», donde «el miedo habla» («el miedo era el alimento de mi patria»), en un tiempo donde «la cobardía ha puesto nombre a todas las cosas». Si la «verdad» ha desertado; si «la verdad dejó de existir en el espacio y en mi espíritu», en el ámbito social, colectivo e histórico, y en la intimidad, después de un tiempo en que «atravesábamos las creencias»; si «la verdad conducía a la traición» y construía la mentira en «un país sin verdad»; si, tal como declara en un momento la voz poética, «No recurriré a la verdad porque la verdad ha dicho no», surge entonces la gran pregunta de Descripción de la mentira: «Y las palabras [...] ¿qué son, qué hacen en mí cuando se ha extinguido la verdad?». ¿Para qué el lenguaje, para qué la palabra si no puede nombrar la verdad, si no tiene capacidad de decir ( «Yo no tengo una esperanza sino una pasión cuyo nombre tú no vas a decirme»), si «cada distancia tiene su silencio»? ¿Qué puede hacer el lenguaje en «un país sin verdad»? La respuesta la otorga el propio título del libro: Descripción de la mentira. El silencio surge entonces como un modo de negación, como una forma de decir no ante una locuacidad irresponsable o ante un lenguaje usurpado. El silencio es el lenguaje del olvido, el lenguaje de la verdad usurpada, negada por la palabra falseadora; es el modo en que se expresan los desheredados de la Historia, aquellos que no tienen voz, aquellos cuya verdad ha sido negada, los invisibles de la sociedad. Otorgar voz a quienes no la tienen, contar la verdad callada sin violar el silencio en que esa verdad radica, descubrir, como quería Walter Benjamin (1990: 182), el rastro de la barbarie que se oculta en el envés de todo documento de cultura, de todo documento de civilización, sin participar a su vez en esa barbarie que se denuncia, es la función de una poesía verdaderamente comprometida, de una cultura decididamente desveladora; la verdad callada, negada en la represión que se impone desde el lenguaje, sólo encuentra su expresión en el silencio:

Sólo hubo resistencia en aquellos cuerpos que antes habían sido castigados y padecieron la incredulidad y se ocultaron en el silencio.

[...]

otra es la ley en las estancias donde el miedo habla.

Donde viven los padres ofendidos.

El silencio es, así, un modo de ocultación, el refugio de la verdad de los humildes, de la pobreza («Agradezco la pobreza para que la pobreza no me maldiga»), tejida con retazos de olvido; es el modo en que «el miedo habla», en 
que el terror que el discurso dominante impone se puede expresar; es también el lenguaje del terror, el lenguaje de la imposición, de la negación:

El silencio y sus círculos, el ácido que depositas sobre mi salud, la suciedad hirviendo dentro de mi alma; éste es el precio de la paz. Acuérdate.

El silencio es el lenguaje en que se expresa «la desesperación que no habla», tal como se dice en Blues castellano; es el lenguaje en que, callando, se expresa esa humanidad doliente y humillada, la mayoría silenciosa que encuentra su solidaridad en el sufrimiento común, en el «cansancio" («mi cansancio es más profundo que tu hermosura»), en la «compasión» («He cesado en la compasión porque la compasión me entregaba a príncipes cuyas medallas se hundían en el corazón de mis hijas»), en la «piedad» («mi desnudez trabaja en la piedad»).

El silencio se convierte, así, en el lenguaje de la resistencia callada ante los discursos aniquiladores, ante la memoria falsificadora, ante la imposición de la mentira que elaboran las palabras, que elabora todo discurso de poder; desestabiliza la paz institucional, la naturalización de las relaciones organizadas desde el relato del poder, pero anuncia una voz callada que sucede a la desesperación:

Ciertamente es una historia horrible el silencio pero hay una salud que sucede a la desesperación.

Acuérdate de la paz en los comercios abandonados, acuérdate de la dulzura en las habitaciones donde se corrompía el olvido. Nadie tenía razón ni esperanza, ¿qué podíamos hacer?

«Es madre de muertos y este poder está en su lengua», se nos dice en otro lugar. Surge así un lenguaje, que nos habla más allá del lenguaje; unas palabras que componen un «relato incomprensible» en el que todo se comprende, porque «sólo es legible el libro de lo incierto», donde se materializa el valor de la «imposibilidad»; un lenguaje que se escribe como búsqueda y no como hallazgo. En este sentido, Descripción de la mentira puede verse como la búsqueda de ese nuevo lenguaje que se materializa en su propia búsqueda, en su propia irrealización; un proyecto de escritura que se realiza como tal proyecto, a la búsqueda de un lenguaje, más allá del silencio, en que la palabra no finja, en que la lengua no mienta. Se trata de la búsqueda de una lengua quemada, de un lenguaje más allá de la destrucción del lenguaje que hable el discurso de la destrucción, el silencio de las ruinas:

¿Por qué quemas tu lengua en los vacíos excavados en pómez [...]?

Puedes cantar en mis manos pero te desdices encima de tu belleza.

Harías mucho mejor acercándote.

Anales, 21, 2009, pp. 101-116 
En Descripción de la mentira acudimos al nacimiento de esa nueva lengua, a la celebración de esa nueva expresividad que se materializa paradójicamente como desplazamiento, como designificación, como un estado permanente de inminencia que nunca aviene, como un más allá del lenguaje, donde se materializa la utopía, que nunca acaba de realizarse, que siempre desplaza sus límites; un lenguaje que apunta sentidos que están más allá de las palabras, deíctico en su significado más preciso; un lenguaje más allá de todo cierre hermenéutico, abierto, porque su sentido no se clausura; un lenguaje incomprensible, impenetrable, que no abarca sino que se abre a la pluralidad:

Yo estoy naciendo en otra especie y el exterior es lívido. Mis animales desconocen la delgadez de tus cuchillos y existen números en mi alma que todavía no comprendo.

En mi saliva hay yodo y polución de alheña, pero mi lengua decolora sombras y enciende luces que no existían.

De este modo, las palabras cobran nueva materialidad; se transforman en hechos lingüísticos, en actos, en el sentido que le otorgaba la escuela oxfordiana (Austin, 1990: passim); adquieren una dimensión de valor en un sistema estructural, que alude constantemente a un elemento que está siempre ausente; instauran el espacio de indeterminación del sentido, donde los significados (y los signos) se diluyen. Los signos verbales se transforman en signos materiales, que formalizan paradójicamente un discurso de la designificación, que buscan la religación del signo con su referente, la sutura simbólica en que acontece el sentido en su negación, por la que las palabras, nombrándose a sí mismas, aluden a un más allá del lenguaje que el propio lenguaje no puede nombrar, al que sólo puede aludir, pero que comienza a existir en el momento en que es nombrado, que pervive en la memoria en cuanto palabra. «Mis palabras podrían atravesar tus labios, entrar despacio en tu existencia; no lo que dicen sino las palabras mismas», leemos en un momento de Descripción de la mentira; y más adelante: «La escritura penetró en tu vientre». Los «signos» («Todos los signos pesan en mi corazón", «Qué signos quedan de las partículas del incendio», «Lames mi piel hasta que brotan signos y tus sollozos forman bóvedas en mi corazón»), en su materialidad lingüística, no remiten a su significado, sino a su referente; se hacen reales en su irrealidad; buscan la religación simbólica con el lenguaje de la realidad, pero sólo pueden aludir, sólo pueden referir su constante desplazamiento, la constante disolución del discurso que enuncian; sólo pueden aludir al silencio que siembran, al hueco que abren, a su carencia. El silencio se convierte entonces en el espacio de la reintegración simbólica («Harías mucho mejor acercándote»), en el espacio de la participación cognoscitiva del sujeto enunciador con la realidad que enuncia, en el espacio de reunión 
en que las palabras cesan, donde olvido y recuerdo se encuentran, donde la memoria y el presente cohabitan, donde lenguaje y silencio se unen, donde se encuentra el yo a sí mismo como extraño en su desaparición: «No he de responder sino reunirme con cuanto está ofrecido en los atrios y en la distribución de los residuos». En ese espacio de participación con lo real, el lenguaje cesa, las palabras callan; sólo pueden aludir a su inminencia, pero nunca a la presencia de su ausencia, al vacío que invocan. El olvido se desplaza; el develamiento del olvido, del hueco irremplazable de la memoria, apunta a nuevos espacios de desvelamiento, a nuevos huecos. El lenguaje, la memoria, la búsqueda de la verdad, siembra nuevos espacios de incertidumbre, nuevas falsedades, abre indudablemente nuevas distancias y, como afirma Descripción de la mentira, «cada distancia tiene su silencio».

Es ahí donde debe incardinarse una dimensión fundamental del silencio en que lee la poesía de Antonio Gamoneda: el silencio es el lenguaje de la desaparición, en que la voz que enuncia el texto poético no se construye en el proceso de enunciación, sino que se disuelve a través de él. Un discurso, como el de Descripción de la mentira, que se niega a cada paso a decir yo, no logra constituir un sujeto, sino que materializa justamente su ausencia, su disolución, su «desaparición». Es ahí donde debemos comprender la movilidad referencial del tú deíctico, que funciona a lo largo de todo el libro y que aparece ahora también nombrado en la «desaparición» («Voy a pactar con tu desaparición», «una forma que describe tu desaparición»), no sólo como un desdoblamiento del yo, sino como una alteridad en la que se construye un diálogo implícito, en que lo perdido, lo olvidado, se recupera en cuanto tal pérdida, en cuanto tal olvido. De este modo el sujeto se nombra como tú, se construye en la alteridad, se dice a sí mismo como otro, marcando así su desplazamiento, la distancia que lo constituye, la desaparición que testimonia, y da cabida a una polifonía de discursos, a un complejo diálogo en que se diluye como enunciador. Descripción de la mentira aparece, desde esta perspectiva, no como el proceso de construcción de un sujeto a través de la enunciación de un discurso, sino como la constatación de su disolución, de su desaparición; apunta de nuevo a un desplazamiento constante del sujeto enunciador del discurso que no se reconoce en las voces que lo enuncian. De ahí que surja la pregunta inquietante al final del texto: «¿Quién habla en ti, quién es la forma de tu rostro?», «¿Quién habla en esta transparencia?». Al final del discurso poético, el sujeto que enuncia (y que es enunciado por) el discurso no logra reconocerse en las voces que enuncia / lo enuncian; la escritura se hace «transparencia», «cesan las escrituras», y con ellas el sujeto que sólo puede constatar su realidad lingüística en su disolución, en su desaparición. Con razón ha afirmado Miguel Casado que la mentira que 
se describe en Descripción de la mentira, no es sólo una mentira histórica, sino una mentira existencial (Gamoneda 2004: 609). Podría decirse que la segunda es la consecuencia última de la primera, en tanto en cuanto que un sistema que se establece en la mentira, en el fingimiento, en el relato falsificador de los hechos, de la Historia, acaba pervirtiendo el relato de la propia existencia que los sujetos se hacen a sí mismos. El propio poeta lo afirma de modo radical: «la naturaleza de los cuerpos es fingir la existencia». En consecuencia, la única forma de ser en la autenticidad es la «desaparición»; la única forma de existencia verdadera es cuando ésta cesa en la muerte. Descripción de la mentira expone, de este modo, un periplo que lleva del «sabor de una desaparición» a la constatación de la lógica mortal como negación absoluta, «tu realidad en la desaparición»; parte de una evocación de lo olvidado para constatar que sólo el olvido existe, que la «desaparición» es el único modo de ser, el único modo de existir, sin fingir la existencia. Apunta, así, a un existencialismo nihilista, que cobra un nuevo giro lingüístico en su exposición, dado que no se busca tanto la identidad en la existencia que acaba constatando la lógica negativa de la muerte, sino la formulación de un sujeto que adquiera coherencia en el discurso de los hechos que relata, y que acaba constatando que la única coherencia posible para evitar la ficción, la mentira, la distancia, que todo relato impone, es su disolución, su «desaparición». Descripción de la mentira no constata tanto la afirmación existencialista del individuo como «ser para la muerte», sino una verdad lingüística que ve al sujeto como una voz que se enuncia en su desaparición. Si el discurso que construye el libro se lee justamente en su borrado, en su silencio, el sujeto que toma voz en ese discurso se realiza justamente en su desaparición. La voz que afirma «conviví con las desapariciones» acaba convirtiéndose ella misma en desaparición a través del discurso que enuncia, que incide en la "transparencia», en la invisibilidad: «mi nombre aumenta en formas invisibles, / y, sometida a aquel silencio, se abre la luz a la desaparición». Toda existencia implica un relato y ese relato impone ficción, distancia, mentira. En la lógica abismal que plantea el poemario y la obra toda de Gamoneda, el único relato verdadero posible de la existencia es su negación («la negación ha tocado mi cuerpo»), su desaparición; el único modo de existir en que los cuerpos no fingen su existencia es justamente en su muerte («Hay un relato y es la humedad que sucedió el mismo día de tu muerte»); el único relato en que el sujeto no finge un discurso falseador, no narra una mentira, es el silencio, la «desaparición».

Aparece, así, clara la coherencia de ese «relato incomprensible» que construye en su disolución Descripción de la mentira, de esa especial memoria del franquismo y de la Transición que construye en su borrado el poemario. El libro, en 
su conjunto, aparece como un proceso de búsqueda polimórfica que lo único que acaba constatando es la búsqueda como proceso. Todo el libro se estructura en torno a un juego de términos que delimitan la tensión de su discurso: olvido / recuerdo, mentira / verdad, silencio / palabra, desaparición / presencia. Esa tensión constata precisamente la distancia entre los elementos que se oponen, el desplazamiento progresivo de uno a otro elemento. De este modo, la búsqueda epistemológica de la verdad acaba derivando en la descripción de la mentira, en el desplazamiento progresivo de la verdad buscada, que sólo puede materializarse en el silencio; que el conocimiento se materializa sólo como ausencia, como distancia. La búsqueda memorialística constata que el recuerdo se materializa en el olvido, que es imposible habitar el olvido, y en el descrédito de todo relato de la memoria. La búsqueda ontológica del ser, de la identidad, muestra que éste sólo existe en su desaparición, en su lógica mortal. Esa búsqueda ontológica deriva en una búsqueda lingüística que patentiza un sujeto que se construye en su disolución, que se construye como alteridad, y un lenguaje que se realiza como distancia, como desplazamiento, como deserción del sentido de los signos. Sólo queda «el silencio y sus círculos» en que Antonio Gamoneda lee su escritura del vacío, su poética de la desocupación; sólo queda la constatación de la distancia, y «cada distancia tiene su silencio». Descripción de la mentira concluye con una pregunta, subrayando la estructura abierta de su discurso: «¿Qué hora es ésta, que yerba crece en nuestra juventud?». Lápidas (1987), cuyo título evoca las «lápidas de mercurio» de Descripción de la mentira, se inicia justo donde el libro anterior concluía (¿se abría?):

Gritos sobre la hierba y el huracán de púrpura.

Giráis envueltos en banderas y exhaláis con dulzura.

Obedecéis a ancianos invisibles cuyas canciones pasan por vuestra lengua.

Ah, jóvenes elegidos por mis lágrimas.

En el discurrir concéntrico de la poesía gamonediana, Lápidas se inicia justo en el último círculo de silencio que había desvelado Descripción de la mentira; avanza un paso más allá en su búsqueda de la verdad, del olvido, de la identidad del lenguaje; avanza un paso más en la lectura del silencio.

\section{BIBLIOGRAFÍA}

AUGÉ, Marc (1998), Las formas del olvido, Barcelona, Gedisa.

AUSTIN, J. L. (1990), Cómo hacer cosas con palabras. Palabras y acciones, Barcelona, Piados.

BENJAMIN, Walter (1990), Discursos interrumpidos, I, Madrid, Taurus.

Anales, 21, 2009, pp. 101-116 
DERRIDA, Jacques (1975), «La farmacia de Platón», en La diseminación, Madrid, Fundamentos.

GAMONEDA, Antonio (2004), Esta luz (Poesía reunida, 1947-2004), epílogo de Miguel Casado, Madrid, Círculo de Lectores-Galaxia Guntenberg.

- Sílabas negras (2006), ed. de Amelia Gamoneda y Fernando R. de la Flor, Madrid-Salamanca, Patrimonio Nacional-Universidad de Salamanca.

VV. AA. (2008), «Antonio Gamoneda. En la lógica mortal», número monográfico de Ínsula, 736.

Fecha de recepción: 25 de junio de 2008

Fecha de aprobación: 28 de octubre de 2008 